\title{
PROPUESTA DE INDICADORES PARA EVALUAR LAS COMPETENCIAS DE ALFABETIZACIÓN MEDIÁTICA EN LAS ADMINISTRACIONES PÚBLICAS
}

\section{Proposal of indicators for the evaluation of media literacy competences in public administrations}

\section{José-Manuel Pérez-Tornero, Santiago Giraldo-Luque, Santiago Tejedor-Calvo y Marta Portalés-Oliva}

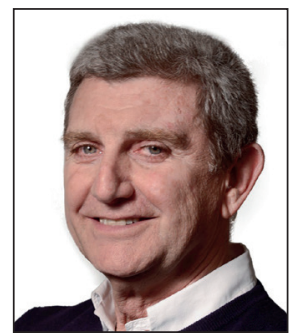

José-Manuel Pérez-Tornero es catedrático y director del Estudio de Doctorado del Departamento de Periodismo de la Universitat Autònoma de Barcelona. Es miembro del equipo directivo de OI2 Observatorio para la innovación de informativos en la sociedad digital (RTVE-UAB-CEU). Director del grupo de investigación Gabinete de Comunicación y Educación. Experto y consultor de la Unesco y la Comisión Europea en servicio público de televisión y de alfabetización digital y mediática. Forma parte como advisor del International Steering Committee (ISC) de la Global Alliance for Partnership on Media and Information Literacy, promovida por la Unesco.

http://orcid.org/0000-0002-8198-3648

josepmanuel.perez@uab.cat

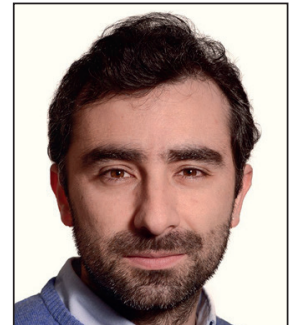

Santiago Giraldo-Luque, profesor del Departamento de Periodismo de la Universitat Autònoma de Barcelona (UAB), es el coordinador del Master de Investigación en Comunicación y Periodismo de la $U A B$ e investigador del Gabinete de Comunicación y Educación de la UAB en donde trabaja temas de participación política, ciudadanía, redes sociales y movimientos sociales, y alfabetización mediática. Es doctor en Comunicación y Periodismo y master en Comunicación y Educación por la $U A B$ y politólogo por la Universidad Nacional de Colombia.

http://orcid.org/0000-0003-0024-7081

santiago.giraldo@uab.cat

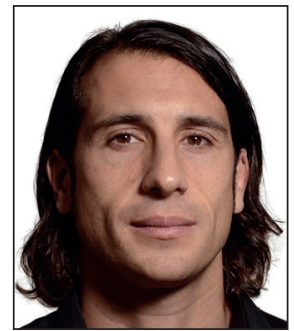

Santiago Tejedor-Calvo es doctor en Periodismo y Ciencias de la Comunicación por la Universitat Autònoma de Barcelona (UAB), doctor en Ingeniería de Proyectos por la Universitat Politècnica de Catalunya (UPC). Es profesor del Departamento de Periodismo y Ciencias de la Comunicación de la $U A B$. Coordina el Gabinete de Comunicación y Educación, grupo de investigación consolidado de la $U A B$. Ha realizado varias estancias de investigación en universidades de América Latina, concretamente de Costa Rica, Colombia, Nicaragua y R. Dominicana.

http://orcid.org/0000-0002-5539-9800

santiago.tejedor@uab.cat

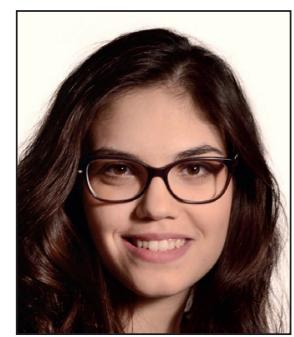

Marta Portalés-Oliva es graduada en Comunicación Audiovisual por la Universidad de Valencia. Realizó un año de programa internacional en la York University Toronto, Canadá, y otro de Erasmus en la Johannes Gutenberg Universität de Maguncia, Alemania. Tras finalizar el Master Oficial de Investigación en Comunicación y Periodismo de la Universitat Autònoma de Barcelona, consiguió una beca de personal investigador en formación para realizar el doctorado. Pertenece al grupo de investigación Gabinete de Comunicación y Educación. Sus líneas de investigación se centran en la alfabetización mediática y el estudio de la imagen.

http://orcid.org/0000-0002-9143-3551

marta.portales@uab.cat 


\section{Resumen}

Se propone un marco de indicadores y un test de autoevaluación de las competencias mediáticas en las administraciones públicas (AAPP), un contexto en el que existen pocas experiencias de evaluación. El estudio toma como base los indicadores de alfabetización mediática $(\mathrm{AM})^{1}$ propuestos en función de los cinco criterios generales de la AM definidos por Pérez-Tornero y Celot (2009): disponibilidad de medios, contexto de AM, uso, comprensión crítica y comunicación. Los marcos iniciales fueron confrontados con los usados en los sistemas de evaluación de competencias mediáticas más conocidos internacionalmente. A partir de la comparación cualitativa de las evaluaciones internacionales, así como de la realización de entrevistas en profundidad, se presenta un test que es aplicado y refinado en un proceso de investigación en que se combinan métodos cuantitativos y cualitativos. El estudio concluye que existen competencias fácilmente evaluables mediante un cuestionario, pero detecta que hay otras, especialmente las referidas a la lectura crítica de la información, que presentan mayor complejidad y que demandan otros tipos de pruebas de comprobación. La aplicación del cuestionario permite obtener recomendaciones útiles para la continuidad y perfeccionamiento de los indicadores de alfabetización mediática dentro de las AAPP.

\section{Palabras clave}

Alfabetización mediática; Competencias; Lectura crítica; Metodología de evaluación; Brecha digital; Indicadores.

\section{Abstract}

A framework of indicators and a media competence self-assessment test for public administrations is proposed, in a field where few evaluation methods have been implemented up until now. The study is based on media literacy (ML) indicators divided in five general criteria defined by Pérez-Tornero and Celot (2009). These are: availability of media, ML context, use, critical understanding, and communication. The initial frameworks were compared with those used in in highly-regarded international media assessment systems. The article presents a test based on the qualitative comparison of international evaluation methods, as well as through in-depth interviews. The proposed tool is applied and refined through a research process that combines quantitative and qualitative methods. The study concludes that competences can be assessed by means of a questionnaire, but also finds that there are others, especially those related to the critical reading of information, that present greater complexity and that demand various types of tests. The application of the survey allows us to obtain useful recommendations for the development and improvement of ML indicators within public administrations.

\section{Keywords}

Media literacy; Skills; Critical reading; Evaluation methodology; Digital gap; Digital divide; Indicators.

Pérez-Tornero, José-Manuel; Giraldo-Luque, Santiago; Tejedor-Calvo, Santiago; Portalés-Oliva, Marta (2018). "Propuesta de indicadores para evaluar las competencias de alfabetización mediática en las administraciones públicas". El profesional de la información, v. 27, n. 3, pp. 521-536.

https://doi.org/10.3145/epi.2018.may.06

\section{Introducción. La administración pública y la alfabetización mediática: una respuesta de servicios orientados a la ciudadanía}

Según Pérez-Tornero, Durán y Tejedor (2015), la progresiva implantación de las tecnologías de la información y la comunicación (TIC) en la producción y en la vida cotidiana, así como el desarrollo de políticas de promoción de la sociedad de la información condujo, desde las primeras décadas del siglo XXI, a la emergencia de:

a) la alfabetización mediática e informacional (AMI) como un tema de agenda pública internacional - muy marcadamente, en las europeas (Pérez-Tornero; Varis; Tapio, 2010; Unesco, 2013; Parlamento Europeo, 2007; Comisión Europea, 2007)-, y

b) un nuevo campo disciplinar (Capello; Felini; Hobbs, 2011).

En este contexto surge la necesidad de elaborar criterios e indicadores que permitan acompañar estrategias y procesos de políticas públicas aplicadas al desarrollo de competencias mediáticas en los individuos y en sus instituciones.
Diversos organismos internacionales y, especialmente la Comisión Europea y la Unesco, han tratado de implantar marcos de evaluación de competencias e indicadores aplicables tanto a países como a individuos o instituciones específicas.

El desarrollo de la sociedad de la información en el siglo XXI coincide con un proceso de modernización de las instituciones públicas respecto a la oferta de servicios a la ciudadanía - gobierno electrónico- y con la apertura de nuevos espacios de participación política - participación electrónica(Sardi; Mlikota, 2002; Horrocks, 2010). La cuestión central es promover las competencias mediáticas e informacionales de los ciudadanos para asegurar una mejor comunicación pública, la transparencia y participación democrática que exige el siglo XXI (Capgemini Consulting, 2007; ONU, 2014 y 2016). Así, la administración o gobierno electrónico (Subirats, 2013) se constituye en un objetivo de las políticas públicas y se concibe como un instrumento esencial para la prestación de servicios públicos eficaces y de mayor calidad, para reducir los plazos de espera de los usuarios y para mejorar la transparencia y la rendición de cuentas en Europa (Comisión Europea, 2006). 
Con un cierto retraso respecto a las organizaciones privadas, el sector público inició su proceso de transformación a través de inversiones en nuevas tecnologías, formación para los empleados públicos y diversas iniciativas de promoción de la sociedad de la información (Costa-Badía; Giraldo-Luque, 2013). Como ha sucedido con las políticas de desarrollo de la sociedad de la información, resulta evidente la necesidad de utilizar también indicadores que sean capaces de diagnosticar las competencias mediáticas de los funcionarios y de las instituciones mismas. De aquí la importancia - como ha ocurrido en otros campos, como en la educación- de crear un marco de evaluación que permita identificar si las instituciones responden adecuadamente a las demandas de innovación en los procesos administrativos y, sobre todo, si las AAPP cuentan con las competencias mediáticas necesarias - tanto a nivel contextual o institucional como en términos de formación de personal- para prestar de forma autónoma los servicios a la ciudadanía.

\section{El sector público inició su proceso de transformación con un cierto retraso respecto a las organizaciones privadas}

Asimismo, los índices globales de innovación y de administración y participación electrónica también definen retos tecnológicos y competenciales tanto para las instituciones como para los individuos que forman parte de las administraciones públicas nacionales. El Global Innovation Index publicado por la Cornell University, la Business School of the World (Insead), y por la Organización Mundial de la Propiedad Intelectual de Naciones Unidas- y el índice de participación electrónica de Naciones Unidas, por ejemplo, sitúan a España en una posición destacada en la provisión de servicios gubernamentales que utilizan las TIC para mejorar la relación entre las administraciones públicas y la ciudadanía (Fundación Telefónica, 2018).

Si la digitalización está en la hoja de ruta de la Estrategia Europa 2020 es necesario conocer los niveles de alfabetización mediática de las instituciones públicas y de los trabajadores del sector, con el objetivo de hacer un diagnóstico que detecte las debilidades y fortalezas en las competencias digitales y mediáticas de las administraciones públicas. Según la Fundación Telefónica (2018) en 2017 el uso de los portales electrónicos de la administración pública se incrementó un $1,3 \%$ y el porcentaje de ciudadanos que interactuó con la administración a través de internet en España fue del 50\%.

A partir del contexto anterior, el estudio describe el proceso de construcción de un sistema de indicadores, así como de su aplicación, a través de una herramienta testada dentro de las AAPP. El texto se basa en el marco general de criterios de evaluación para medir los niveles de alfabetización mediática (AM) definidos por la Comisión Europea (Pérez Tornero; Celot, 2009) y toma en consideración algunos de los criterios señalados en los diversos informes sobre indicadores de la Unesco como el Global MIL Assessment Framework (2013). Pérez-Tornero y Celot (2009) proponen, como se aprecia en la tabla 1, una distribución holística de los criterios de competencias mediáticas a partir de la disponibi- lidad de medios, el contexto de AM, el uso, la comprensión crítica y la comunicación /participación.

\section{Medir la alfabetización mediática a partir de indicadores}

Los estudios sobre indicadores para la medición de la de AM dentro de las AAPP son escasos, sobre todo en comparación con la gran disponibilidad de propuestas de aplicación y evaluación de AM tanto en términos generales como en contextos educativos.

En relación con la definición de indicadores en España destacan diversos esfuerzos por diagnosticar las competencias mediáticas y audiovisuales (Ferrés-Prats, 2007; Ferrés-Prats; Piscitelli, 2012; Pérez-Rodríguez; Delgado-Ponce, 2012; Area, 2015).

A nivel internacional sobresalen también las aportaciones sobre indicadores de Pérez-Tornero y Celot (2009); Tilleul, Fastrez y De-Smedt (2014); Buckingham (2014); Ng, (2011); y Park (2012), entre otros.

Finalmente, respecto a la evaluación de los mismos, destacan propuestas internacionales como la del Global MIL Assessment Framework de la Unesco (2013) para la evaluación de la AM en países. En la bibliografía sobre evaluación de AM en centros educativos destacan los esfuerzos de Pereira, Pinto y Moura (2105) en Portugal, el test computarizado y adaptativo aplicado en Austria de Hermida y Hielscher (2017) o el trabajo de Aguaded-Gómez, Ferrés-Prats, Cruz-Díaz, Pérez-Rodríguez y Sánchez-Carrero (2011) que analizó el grado de competencias mediáticas de los ciudadanos en Andalucía.

Tabla 1. Criterios de competencias mediáticas a partir de la propuesta de Pérez-Tornero y Celot (2009)

\begin{tabular}{|c|c|}
\hline Criterio de AM & Componente \\
\hline \multirow{6}{*}{$\begin{array}{l}\text { Disponibilidad de } \\
\text { medios }\end{array}$} & Internet \\
\hline & Radio \\
\hline & Periódicos \\
\hline & Televisión \\
\hline & Salas de cine \\
\hline & Teléfonos móviles \\
\hline \multirow{4}{*}{$\begin{array}{l}\text { Contexto } \\
\text { mediático }\end{array}$} & Educación en medios \\
\hline & Autoridades de regulación y legislación \\
\hline & Sociedad civil \\
\hline & Industria mediática \\
\hline \multirow{3}{*}{ Uso } & Habilidades de uso del ordenador y de internet \\
\hline & Uso activo y balanceado de los medios \\
\hline & Uso avanzado de internet \\
\hline \multirow{3}{*}{$\begin{array}{l}\text { Comprensión } \\
\text { crítica }\end{array}$} & Comprensión del contenido mediático \\
\hline & Comportamiento del usuario en la Red \\
\hline & $\begin{array}{l}\text { Conocimiento sobre los medios de comunicación } \\
\text { y sobre su regulación }\end{array}$ \\
\hline \multirow{3}{*}{ Comunicación } & Creación de contenido \\
\hline & Relaciones sociales \\
\hline & Participación \\
\hline
\end{tabular}


Por lo que se refiere a educación, analizada la bibliografía correspondiente, se deduce que existen numerosos estudios sobre la integración de AM (Aparici; Matilla, 2016; Frau-Meigs; Vélez; Flores, 2017) en centros educativos de primaria y secundaria (Medina-Cambrón; Ballano-Macías, 2015); en la universidad (Llorente; Cabero, 2010; López-Romero; Aguaded-Gómez, 2015; Tucho; Fernández-Planells; Figueras-Maz, 2015); en el aprendizaje a lo largo de la vida (Abad, 2014), como herramienta educativa para la inclusión social (Ribeiro-Pessoa; Hernández-Serrano; Muñoz-Rodríguez, 2015) o en contextos tan variados como en prisiones (Contreras-Pulido, 2014). En lo que se refiere a Europa, cabe destacar el estudio del Observatorio Audiovisual Europeo (2017) Mapping of media literacy practices and actions in EU-28, dentro del cual se destaca el sector educativo como línea de acción de su implementación práctica.

En contraposición al sector educativo y empresarial, los estudios empíricos sobre la aplicación de indicadores y sistemas de evaluación de la AM en las AAPP son limitados. Existe también un vacío respecto al análisis de habilidades técnicas y al uso de dispositivos electrónicos a nivel individual y, especialmente, en relación con la evaluación de la comprensión crítica y creación de contenido. Los trabajos existentes se concentran en empresas pequeñas (Martí-
nez-Cerdá; Torrent-Sellens, 2014) o en la oferta de servicios asociados al gobierno electrónico (Capgemini Consulting, 2010 y 2012).

\section{En contraposición al sector educativo y empresarial, los estudios empíricos so- bre la aplicación de indicadores y siste- mas de evaluación de la AM en las AAPP son limitados}

Dentro del marco europeo, los informes y recomendaciones sobre la implementación del gobierno electrónico, que, de algún modo, involucran las competencias mediáticas, se concentran en estudios nacionales - es el caso de Dinamarca (Vergez; Wang, 2010) o Lituania (Cabinet of Ministers of the Republic of Latvia, 2008) - o en mediciones bienales sobre los servicios ofertados en Europa (Lorincz et al., 2009).

La propuesta de Hemant y Nowbutsing (2010) aporta contenido cualitativo y propone la innovación sobre las capacidades tecnológicas de las personas, así como la facilidad de acceder a las TIC, dentro y fuera de las instituciones públicas. En la misma línea, Hrdinová, Helbig y Peters (2010)

Tabla 2. Pruebas de medición de competencias mediáticas analizadas

\begin{tabular}{|c|c|c|c|}
\hline Nombre de la iniciativa & Autor/es & Año & $\begin{array}{l}\text { País / región de } \\
\text { aplicación }\end{array}$ \\
\hline $\begin{array}{l}\text { Bibliotecas escolares, ¿entre interrogantes? Herramienta de autoevaluación. } \\
\text { Preguntas e indicadores para mejorar la biblioteca }\end{array}$ & Miret y Armendano & 2011 & España \\
\hline $\begin{array}{l}\text { Competencia mediática. Investigación sobre el grado de competencia en la } \\
\text { ciudadanía en España }\end{array}$ & Ferrés-Prats et al. & 2011 & España \\
\hline IT Card & European Software Institute & n. d. & España \\
\hline E-skills career tool: linking ICT skills to jobs & ECDL Foundation & 2010 & Europa \\
\hline Identify your ICT needs & European Commission & 2010 & Europa \\
\hline Testing and refining criteria to assess media literacy levels in Europe & European Commission & 2011 & Europa \\
\hline Community survey on ICT usage and e-commerce in enterprises & European Commission & 2013 & Europa \\
\hline European Union survey on ICT usage in households and by individuals & Eurostat & 2013 & Europa \\
\hline $\begin{array}{l}\text { Survey of schools: ICT in education. Benchmarking access, use and attitudes } \\
\text { to technology in Europe's schools. Annex 3: Three survey questionnaires }\end{array}$ & $\begin{array}{l}\text { European Schoolnet; Université de } \\
\text { Liège, Psychology and Education }\end{array}$ & 2013 & Europa \\
\hline C2i - Certificat informatique et internet. Niveau 1 & Ministère de l'Éducation Nationale & 2011 & Francia \\
\hline B2i Brevet informatique et internet. Lycée. Feuille de position B2i & Ministère de l'Éducation Nationale & 2006-2011 & Francia \\
\hline eLemér (Teacher and student questionnnaire) & $\begin{array}{l}\text { OFI (Instituto de Investigación y } \\
\text { Desarrollo Educativo) }\end{array}$ & 2010 & Hungría \\
\hline $\begin{array}{l}\text { Better public services through e-government: Academic article in support of } \\
\text { better public services through e-government }\end{array}$ & Margetts y Dunleavy & 2002 & Reino Unido \\
\hline Questionnaire - children aged 5-15 (Master) & Ofcom & 2009 & Reino Unido \\
\hline A media literacy quiz & $\begin{array}{l}\text { USC Annenberg School for Commu- } \\
\text { nication and Journalism }\end{array}$ & n. d. & Estados Unidos \\
\hline National assessment program. ICT literacy 2011. Years 6 and 10 report & Ainley et al. & 2012 & Australia \\
\hline $\begin{array}{l}\text { Programme for International Student Assessment (PISA) } 2009 \text { results: Stu- } \\
\text { dents online: Digital technologies and performance (Volume VI) }\end{array}$ & $O E C D$ & 2011 & Global \\
\hline Nonprofit social media policy workbook & Idealware & 2012 & Global \\
\hline $\begin{array}{l}\text { Programme for the international assessment of adult competencies (Piaac) } \\
\text { background questionnaire }\end{array}$ & $O E C D$ & 2013 & Global \\
\hline
\end{tabular}


plantean la construcción de una política pública de impulso a la utilización de los medios sociales por parte de las agencias gubernamentales.

Desde otro enfoque, los informes Reina (2016) e IRIA (2016), elaborados por la Dirección de Tecnologías de la Información y las Comunicaciones (DTIC) en España, señalan las condiciones de las AAPP respecto al uso de equipamientos físicos, software, servicios informáticos, servicios de telecomunicaciones, personal y otros aspectos técnicos.

\section{Metodología}

La construcción y aplicación de un marco de indicadores y el diseño de un test o cuestionario, considerado como instrumento de medición centrada en las competencias mediáticas específicamente para las AAPP se llevó a cabo

a) con una metodología cualitativa (Tayie, 2005, p. 86), que integró procedimientos de análisis y desarrollo; y mediante

b) una aplicación cuantitativa del cuestionario mencionado.

Dentro del aspecto cualitativo, en la primera etapa, el proyecto realizó una exploración documental sobre los indicadores y sistemas de medición de habilidades sobre competencias mediáticas en general. Para ello, se seleccionaron y analizaron las principales referencias sobre indicadores, así como los tests y pruebas existentes relacionadas con la AM.

Una vez se dispuso de un estudio documental amplio, se llevaron a cabo una serie de entrevistas en profundidad para identificar los insumos teóricos y prácticos de utilidad para la construcción de indicadores sobre AM específicos para las AAPP.

Esta primera etapa siguió 3 instrumentos metodológicos:

1. Exploración bibliográfica de estudios empíricos previos (Pérez-Tornero; Celot, 2009; Tilleul; Fastrez; De-Smedt, 2014; Buckingham, 2014; Ng, 2011; Park, 2012; Vergez; Wang, 2010; Cabinet of Ministers of the Republic of Latvia, 2008; Lorincz et al., 2009; Capgemini Consulting, 2010 y 2012);

2. Análisis y sistematización de 19 pruebas de detección de los niveles de competencias mediáticas (ver tabla 2), a través de una clasificación de sus preguntas en los indicadores y criterios de los marcos generales de competencias en AM para identificar cuáles eran aplicables a las AAPP; y

3. Cinco entrevistas en profundidad a actores de dos AAPP ${ }^{3}$ para identificar otras necesidades emergentes en la cotidianidad de la administración.

Tras compilar los indicadores básicos a partir de las tres fuentes anteriores, el proyecto examinó los criterios y las preguntas que, para cada uno de ellos, existían en las pruebas analizadas. Se comprobaron, asimismo, las ausencias de contenido en las pruebas que respondieran a las necesidades identificadas en las entrevistas. A partir de estos insumos, se pasó a la segunda etapa que se centró en la construcción y aplicación de una prueba piloto de un cuestionario para medir los indicadores relacionados con la AAPP.

El cuestionario fue elaborado a partir de preguntas cerradas con varias alternativas de respuesta que integraba, de forma balanceada, preguntas sobre todos los criterios (Hernández-Sampieri; Fernández-Collado; Baptista-Lucio, 2006, p. 171). La construcción del cuestionario se realizó en varios pasos ilustrados en la figura 1 .

El cuestionario se aplicó, en primer lugar, como estudio piloto por un ayuntamiento (Sant Cugat del Vallés, Barcelona), con una muestra de 47 individuos quienes además aportaron - a través de respuestas abiertas dentro del mismo cuestionario- sus comentarios de forma cualitativa. La primera aplicación facilitó el ajuste de las preguntas y comprobar la comprensión del cuestionario de parte del encuestado. Asimismo, permitió la medición del tiempo de respuesta con la intención de reducir al máximo su aplicación. Posteriormente, se realizó una segunda versión del mismo que fue sometido a un nuevo proceso cualitativo de aplicación. Cada una de las validaciones -6 en total, realizadas con trabajadores de la AAPP - fue seguida por un investigador que tomaba nota de los comentarios, sugerencias y críticas que realizaba el encuestado (Hernández-Sampieri, 2006, p. 178). Los comentarios recibidos permitieron reestructurar de nuevo el cuestionario, en función de repeticiones y preguntas difíciles de entender, al tiempo que se realizó una nueva versión del estudio piloto más corta y concentrada.

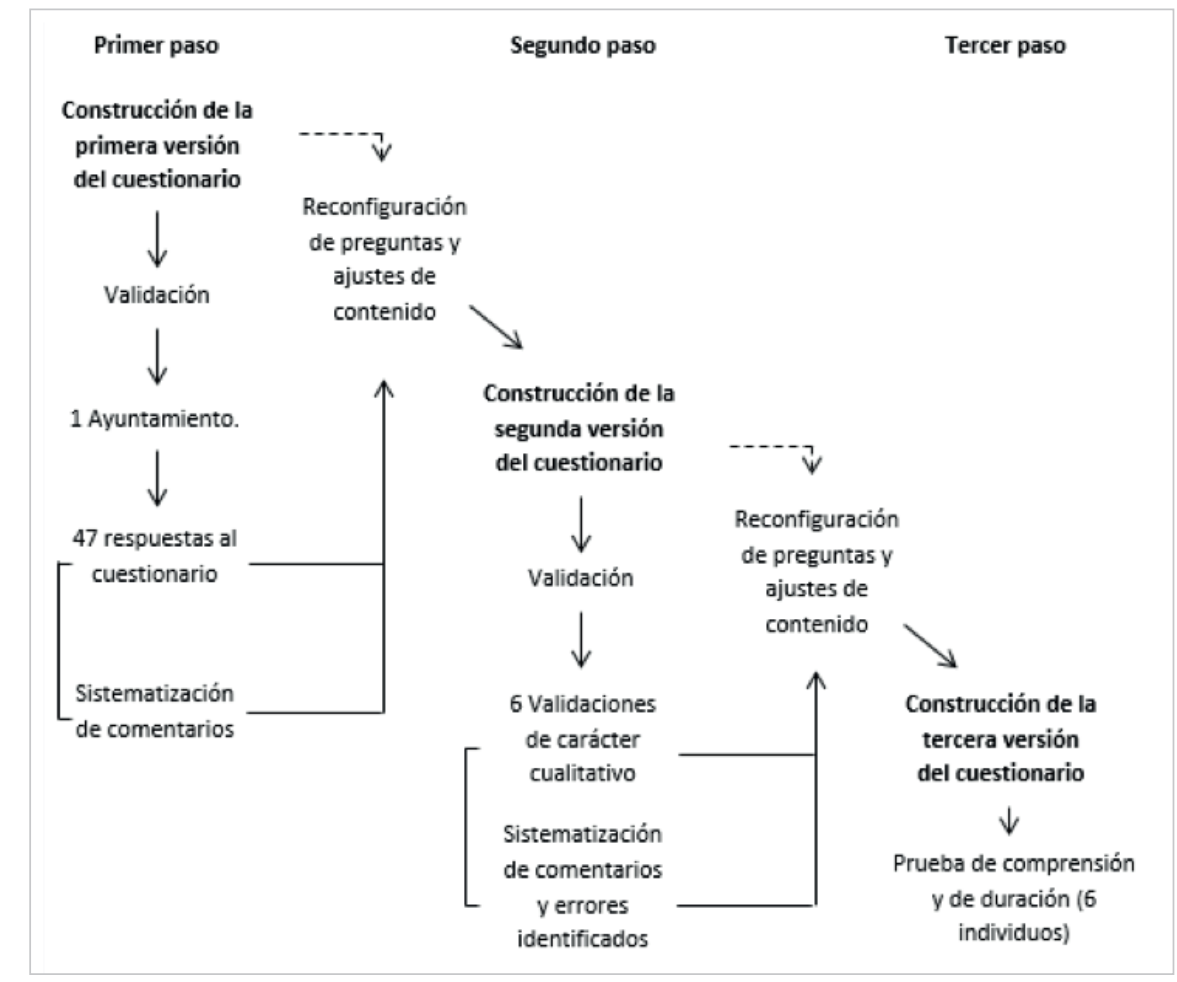

Figura 1. Proceso de construcción del cuestionario para las AAPP 
Tabla 3. Criterios y componentes de alfabetización mediática identificados en la documentación previa (administraciones públicas)

\begin{tabular}{|c|c|c|}
\hline Criterio de AM & Componente & General/específico \\
\hline \multirow{3}{*}{ Disponibilidad de medios } & Internet & \multirow{2}{*}{ General } \\
\hline & Dispositivos & \\
\hline & Recursos & General y específico \\
\hline \multirow{2}{*}{ Contexto mediático } & Educación en medios & General \\
\hline & Regulación y legislación & General y específico \\
\hline \multirow{3}{*}{ Uso } & Habilidades de uso del ordenador y de internet & \multirow{2}{*}{ General } \\
\hline & Uso activo y balanceado de los medios & \\
\hline & Uso avanzado de internet & General y específico \\
\hline \multirow{3}{*}{ Comprensión crítica } & Comprensión del contenido mediático & \multirow{7}{*}{ General } \\
\hline & Comportamiento del usuario en internet & \\
\hline & Conocimiento sobre los medios de comunicación y su regulación & \\
\hline \multirow{5}{*}{ Comunicación } & Creación de contenido & \\
\hline & Relaciones sociales & \\
\hline & Participación & \\
\hline & e-educación & \\
\hline & Gobierno electrónico & Específico \\
\hline
\end{tabular}

Adaptado de Pérez-Tornero y Celot (2009)

Se creó una tercera versión con una última aplicación cualitativa a 6 individuos, bajo la supervisión de un investigador, que permitió comprobar tanto su legibilidad como su ajuste a rangos de tiempo adecuados para su aplicación (anexo 1).

La tercera etapa a nivel metodológico consistió en la aplicación del cuestionario en un estudio piloto que permitió evaluar su capacidad para medir los niveles de competencias mediáticas de las AAPP. El índice de respuestas altamente positivas en algunos aspectos de autoevaluación, sobre todo en lo referente a las competencias técnicas en niveles altos o muy altos, o en capacidades críticas, permitió establecer la potencialidad del cuestionario como mecanismo de evaluación competencial. En esta etapa participaron 58 individuos de tres ayuntamientos: 8 de Colmenarejo (Madrid), 10 de Gironella (Barcelona) y 40 de El Masnou (Barcelona). Los sujetos seleccionados para la muestra, de tipo no probabilístico e intencional (Tayie, 2005), se seleccionaron con el objetivo de que participaran ayuntamientos de poblaciones diversas en número. La muestra incluía municipios que oscilaban entre los 4.000 y los 21.000 habitantes.

\section{Resultados}

Los resultados se dividen en cuatro secciones:

- detección y análisis de indicadores;

- identificación de competencias específicas de las AAPP;

- propuesta de indicadores; y

- aplicación empírica de indicadores en el estudio piloto.

\subsection{Detección y análisis de indicadores de alfabetiza- ción mediática (AM) para administraciones públicas (AAPP)}

De manera general, y de acuerdo con los hallazgos identificados en la revisión del estado de la cuestión de la temática, no fueron hallados marcos de competencias mediáticas que pudieran aplicarse específicamente sobre las AAPP. Sin embargo, sí existen estudios relacionados con la oferta de servicios sobre administración electrónica, además de recomendaciones para promover la AM en instituciones y documentos que analizan los elementos de contexto que pueden determinar el desarrollo de la AM en una institución.

A partir de la propuesta de Pérez-Tornero y Celot (2009) - ver tabla $1-$, las entre-

Figura 2. Análisis de 19 pruebas. Componentes de competencias individuales 
vistas realizadas a responsables dentro de las AAPP y la revisión de 19 pruebas aplicadas en varios países sobre las competencias mediáticas, el estudio identificó los criterios y componentes que se recogen en la tabla 3 y que resultan fundamentales para la definición de los indicadores. En la relación de criterios se establecen tanto componentes generales para el desarrollo de la AM en diferentes contextos, como específicos para el tipo de tareas y actuaciones concretas de las AAPP.

De acuerdo con el análisis de las pruebas sobre AM (Giraldo-Luque et al., 2014), los componentes relacionados con las habilidades individuales tenían más protagonismo que los items sobre factores del entorno de la AM. Asimismo, las capacidades asociadas a sus relaciones sociales - comunicativas - quedaban reducidas a una quinta parte del total de preguntas sobre competencias personales (figura 2) encontradas en el conjunto de las pruebas analizadas. El análisis comparativo entre el marco de criterios identificados en la tabla 1 y el resultado del análisis de las pruebas sobre AM (figura 2) marca un desequilibrio entre la evaluación de criterios y señala ausencias significativas que limitan la perspectiva del estudio sobre las competencias mediáticas. El cuestionario diseñado reajusta la composición de las pruebas con el fin de equilibrar la evaluación y dar mayor peso a componentes hasta ahora relegados, tales como la comunicación y el comportamiento del usuario. En todo caso, el citado desequilibrio se entiende porque los criterios generales están referidos a países, y por tanto a condiciones generales, y el cuestionario a individuos concretos.

\subsection{Identificación de competencias específicas para la administración pública}

El diseño de indicadores intentó también construir, dada su especificidad, elementos de evaluación específica en función del ámbito estudiado: las AAPP. El cuestionario identificó cuatro componentes en los que se incluyen algunos de los indicadores específicos relacionados con las AAPP y que fueron obtenidos a partir del análisis de los cuestionarios pero, sobre todo, de las entrevistas en profundidad.

1) En términos de recursos y disponibilidad mediática, el cuestionario pregunta por elementos relacionados con la transparencia administrativa, por la publicación de datos públicos, y por los recursos mediáticos que la institución utiliza para la gestión de la información.

2) Dentro del criterio de contexto mediático, la herramienta indaga sobre los programas de formación en TIC orientados a dotar de habilidades específicas a los funcionarios de la administración.

3) Las competencias referidas a las habilidades individuales se concentran en los componentes de uso avanzado de internet (criterio de uso). Por último, en relación a las competencias de tipo social, el cuestionario incluye

4) el gobierno electrónico, como parte del criterio de comunicación/participación.

\subsection{Propuesta de indicadores sobre la AM en las AAPP}

Los insumos recibidos para la construcción del cuestionario permiten diseñar un marco de indicadores que procura suplir las lagunas encontradas en los procesos metodológicos previos. De acuerdo con los hallazgos resaltados, los indicadores preparados para la evaluación de las competencias mediáticas de las AAPP se presentan a través del siguiente marco de criterios, componentes e indicadores. La reestructuración mantiene la propuesta de Pérez-Tornero y Celot (2009) y presenta un nuevo balance entre los criterios, profundiza en las condiciones particulares de las instituciones públicas e incluye nuevas necesidades relativas a las AAPP.

La tabla 4 otorga especificidad a las competencias mediáticas de las AAPP en relación a los criterios generales de AM esperados de la ciudadanía. El nuevo cuestionario, compuesto en total por 125 preguntas, distribuye los interrogantes de acuerdo con la gráfica (figura 3 ) que detalla el peso de cada criterio en el cuestionario. La figura 3 así como la tabla 5 muestran un nuevo equilibrio en la distribución de preguntas sobre los indicadores en el cuestionario propuesto que otorga pesos específicos a cada criterio de forma más coherente. Resuelve así uno de los principales problemas identificados en las pruebas analizadas en la fase previa de la investigación.

El cuestionario evita así el protagonismo del criterio de uso, presente en los estudios precedentes, y otorga importancia a los niveles superiores de la AM: la lectura crítica y la comunicación. Asimismo, la herramienta busca el equilibrio entre las habilidades individuales y sociales, otro de los aspectos identificados como problemáticos en el análisis de las pruebas realizado.

Destaca también el peso de elementos específicos de las AAPP: recursos mediáticos de la institución, planes de for-

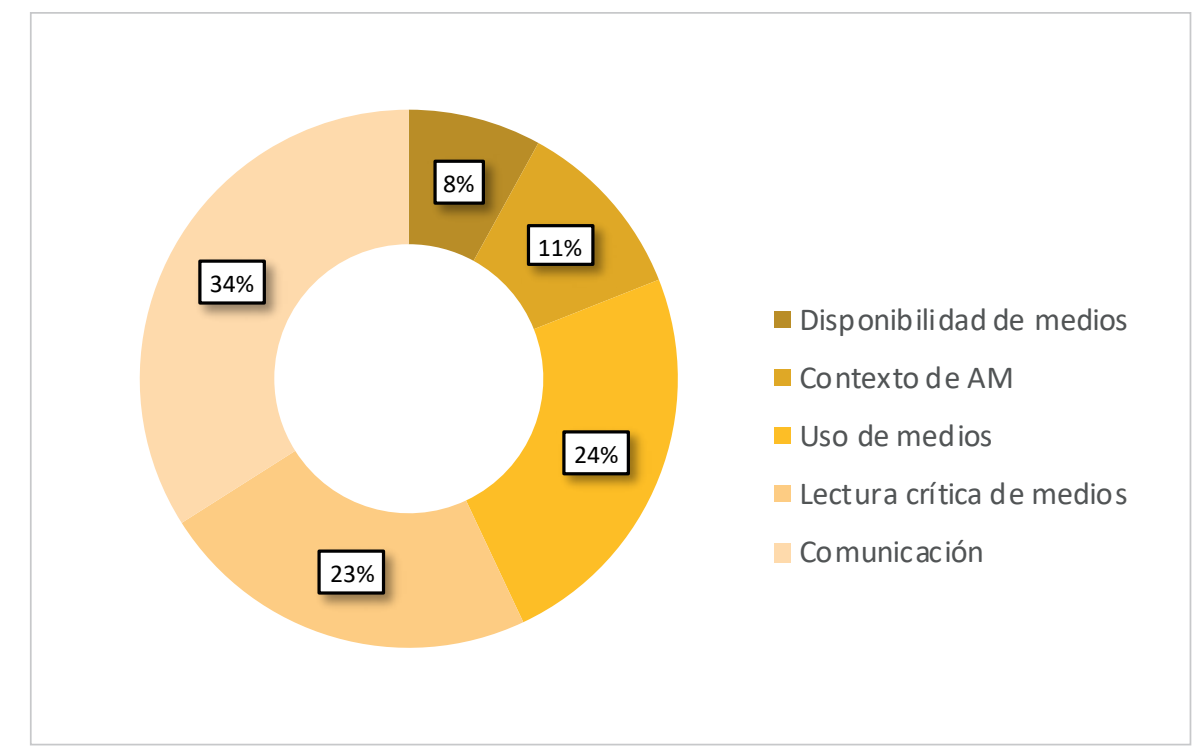

Figura 3. Distribución porcentual de preguntas por criterio 
Tabla 4. Marco de indicadores las administraciones públicas

\begin{tabular}{|c|c|c|}
\hline Criterios & Componentes & Indicador \\
\hline \multirow{3}{*}{$\begin{array}{l}\text { Disponibilidad de } \\
\text { medios y acceso }\end{array}$} & Internet & Disponibilidad de acceso a internet en la institución \\
\hline & Dispositivos & Disponibilidad de acceso a dispositivos en la institución \\
\hline & Recursos disponibles & Disponibilidad de recursos mediáticos en la institución \\
\hline \multirow{3}{*}{ Contexto de AM } & \multirow{2}{*}{ Educación en medios (plan de formación) } & Existencia de planes de formación en AM \\
\hline & & Ejecución del plan de formación \\
\hline & $\begin{array}{l}\text { Regulación de uso de internet, medios y } \\
\text { dispositivos }\end{array}$ & $\begin{array}{l}\text { Existencia de regulación en el uso de internet, medios de comunicación y } \\
\text { dispositivos dentro de la institución }\end{array}$ \\
\hline \multirow{10}{*}{ Uso (individuos) } & \multirow{2}{*}{ Habilidades de uso del ordenador y de internet } & Habilidades de uso del ordenador \\
\hline & & Habilidades de uso de internet \\
\hline & Uso activo y balanceado de los medios & Uso/frecuencia de medios de comunicación \\
\hline & \multirow{7}{*}{ Uso avanzado de internet } & Uso de herramientas avanzadas para ocio/trabajo \\
\hline & & Compra/venta por internet \\
\hline & & Uso de lenguajes propios de internet (html) \\
\hline & & Resolución de problemas técnicos \\
\hline & & Capacidad de búsqueda analítica \\
\hline & & Almacenamiento y recuperación de información \\
\hline & & Identificación de necesidades y respuestas a partir de las TIC \\
\hline \multirow{10}{*}{$\begin{array}{l}\text { Lectura crítica } \\
\text { (individuos) }\end{array}$} & \multirow{3}{*}{ Comprensión del contenido mediático } & Lectura de textos mediáticos \\
\hline & & Clasificación de textos \\
\hline & & Distinción de contenido mediático \\
\hline & \multirow{3}{*}{ Comportamiento del usuario en internet } & Exploración y búsqueda crítica en internet \\
\hline & & Evaluación del contenido mediático \\
\hline & & $\begin{array}{l}\text { Adaptación, configuración, aplicación e identificación de patrones de } \\
\text { seguridad en dispositivos y programas }\end{array}$ \\
\hline & \multirow{4}{*}{$\begin{array}{l}\text { Conocimiento sobre los medios de } \\
\text { comunicación y su regulación }\end{array}$} & Conocimiento sobre la concentración/propiedad de los medios \\
\hline & & Conocimiento sobre la regulación de los medios \\
\hline & & Conocimiento sobre los derechos de autor y licencias \\
\hline & & $\begin{array}{l}\text { Conocimiento sobre los patrones de seguridad de las plataformas de } \\
\text { intercambio de información }\end{array}$ \\
\hline \multirow{13}{*}{$\begin{array}{l}\text { Comunicación } \\
\text { (ámbito social) }\end{array}$} & \multirow{3}{*}{ Creación de contenido } & Habilidades de producción en medios \\
\hline & & Integración y reelaboración de contenidos \\
\hline & & Creación de contenido mediático \\
\hline & \multirow{3}{*}{ Relaciones sociales } & Compartir contenido mediático \\
\hline & & Interactuar a partir de las TIC \\
\hline & & Colaborar utilizando las TIC (networking) \\
\hline & Participación & Participación ciudadana \\
\hline & e-learning & Interacción TIC con fines educativos (formal, informal, no formal) \\
\hline & \multirow{5}{*}{ Gobierno electrónico } & Informar a la ciudadanía \\
\hline & & Atención a la ciudadanía \\
\hline & & Fomentar la participación de la ciudadanía \\
\hline & & Ofrecer servicios a la ciudadanía \\
\hline & & Rendir cuentas (transparencia) \\
\hline
\end{tabular}

mación, uso avanzado de internet y gobierno electrónico. La tabla 4 detalla la estructura del cuestionario en relación con los cinco criterios y al total de preguntas. El detalle de la distribución por componentes se explica porque es el componente mismo el que desarrolla el criterio. Los componentes se resuelven a través de los indicadores que se construyen con las preguntas del cuestionario.

\subsection{Análisis de los indicadores y criterios aplicados en el estudio piloto}

Se describen a continuación los cinco criterios evaluados: disponibilidad, contexto de AM, uso, lectura crítica y comunicación.

Aunque el cuestionario aporta información, los criterios de disponibilidad y contexto de AM pueden ser validados por 
Tabla 5. Propuesta de cuestionario para las administraciones públicas: distribución de los componentes en porcentajes

\begin{tabular}{|c|c|c|c|c|}
\hline Criterios & Componentes & $\begin{array}{l}\text { Porcentaje den- } \\
\text { tro del criterio }\end{array}$ & $\begin{array}{l}\text { Porcentaje dentro } \\
\text { del cuestionario }\end{array}$ & $\begin{array}{l}\text { Número de } \\
\text { preguntas }\end{array}$ \\
\hline \multirow{3}{*}{$\begin{array}{l}\text { Disponibilidad de medios } \\
\text { y acceso }\end{array}$} & internet & 10,0 & 0,8 & 1 \\
\hline & Dispositivos & 50,0 & 4,0 & 5 \\
\hline & Recursos disponibles & 40,0 & 3,2 & 4 \\
\hline \multirow{2}{*}{ Contexto de AM } & Educación en medios (plan de formación) & 35,7 & 4,0 & 5 \\
\hline & Regulación de uso de internet, medios y dispositivos & 64,3 & 7,2 & 9 \\
\hline \multirow{3}{*}{ Uso } & Habilidades de uso del PC y de internet & 20,0 & 4,8 & 6 \\
\hline & Uso activo y balanceado de los medios & 36,7 & 8,8 & 11 \\
\hline & Uso avanzado de internet & 43,3 & 10,4 & 13 \\
\hline \multirow{3}{*}{ Lectura crítica } & Comprensión del contenido mediático & 28,6 & 6,4 & 8 \\
\hline & Comportamiento del usuario en internet & 35,7 & 8,0 & 10 \\
\hline & $\begin{array}{l}\text { Conocimiento sobre los medios de comunicación y su } \\
\text { regulación }\end{array}$ & 35,7 & 8,0 & 10 \\
\hline \multirow{5}{*}{ Comunicación } & Creación de contenido & 32,6 & 11,2 & 14 \\
\hline & Relaciones sociales & 30,2 & 10,4 & 13 \\
\hline & Participación & 16,3 & 5,6 & 7 \\
\hline & e-learning & 2,3 & 0,8 & 1 \\
\hline & Gobierno electrónico & 18,6 & 6,4 & 8 \\
\hline
\end{tabular}

otro tipo de instrumentos de investigación. En este caso, las entrevistas permiten comprobar la información suministrada. El análisis de contenido de documentación oficial o cuestionarios online permite identificar de forma fiable recursos, planes de formación, normativas de regulación de dispositivos y espacios mediáticos de la institución, así como la información pública sobre temas clave. En este punto también puede ser interesante la descripción de los servicios de comunicación de la AAPP en cuestión. Algunas preguntas para comprobar el conocimiento de los funcionarios sobre los items anteriores permitirían contrastar la información recopilada para definir mejor el contexto institucional.

En el caso de las habilidades individuales, los indicadores permiten hacer un diagnóstico de las competencias básicas. En el primer componente del cuestionario, los indicadores permiten construir un perfil de las personas en relación a su consumo de medios y al uso de los dispositivos. Es, sin embargo, un perfil limitado por la opinión del encuestado, ya que no se trata de un cálculo preciso del tiempo de consumo mediático.

El ítem relativo a las habilidades básicas del usuario en ordenadores e internet cuenta también con la autoevaluación por parte del usuario. El cuestionario permite identificar, sin embargo, competencias de uso de internet y programas específicos de una manera rápida y concreta. También reconoce tendencias de uso, habilidades compartidas y competencias poco desarrolladas en el entorno estudiado.

Por último, el cuestionario analiza el uso avanzado de internet por parte de los encuestados. Permite comprender habilidades generales pero también específicas en función de sus tareas laborales y propone una serie de preguntas sobre plataformas de trabajo colaborativo.
El cuestionario se plantea como una opción que recoge información general de las competencias individuales en relación al uso, sobre todo de manera técnica. Otras propuestas cualitativas, como la realización de una prueba práctica en la que se evidencien las capacidades individuales, ayudarían a identificar mejor las habilidades de los funcionarios, pero ello requeriría más recursos y más tiempo.

En el caso del componente sobre la comprensión del contenido mediático, el cuestionario plantea una autovaloración en la que los encuestados juzgaron muy positivamente sus competencias. En este caso es necesario modificar las preguntas para valorar más objetivamente las capacidades individuales de comprensión de la información que emiten los medios de comunicación en diferentes formatos y con distintas intencionalidades.

Las preguntas planteadas sobre el comportamiento del usuario en internet, segundo ítem de la lectura crítica, permiten recoger el conocimiento y tipo de acciones que los individuos realizan relacionadas con la seguridad o con la publicación de contenido en redes sociales. Aunque los datos son relevantes, el tipo de preguntas realizadas limita las respuestas de los usuarios a una autoevaluación, que no comprueba la capacidad crítica del individuo.

En el último componente del criterio, conocimiento sobre los medios de comunicación y su regulación, se incluyen preguntas tipo test con una única respuesta correcta que examinan los conocimientos del usuario y permiten identificar si el encuestado conoce su entorno mediático. Este tipo de preguntas permite obtener datos objetivos sobre el conocimiento del usuario de la regulación, la titularidad o la identificación de diferencias de contenido en los medios de comunicación.

El criterio de comunicación también se resuelve a partir de 
indicadores que se presentan mediante preguntas auto-evaluativas. Al mismo tiempo se plantea un número reducido de preguntas que intentan explorar los diferentes campos y componentes, pero que no reproduce de forma exhaustiva todas y cada una de las competencias que se pretenden medir.

A pesar de ello, las preguntas referidas al criterio de comunicación construyen una importante base de datos que facilita un cruce de variables interesante entre distintos tipos de usuario y permiten análisis alternativos a partir de verificaciones entre criterios diferentes.

Si bien es cierto que algunos de los componentes pueden ampliarse en función de nuevas actividades y procesos, las preguntas formuladas responden a un objetivo básico: evidenciar tendencias de uso de las aplicaciones de internet para la creación de contenido, la socialización, el intercambio de conocimiento y la participación. El cuestionario otorga un importante número de preguntas al criterio de comunicación y da equilibrio a las habilidades sociales, infra-representadas en los estudios anteriores.

Para garantizar la prestación de servicios las AAPP necesitan alcanzar competencias mediáticas: alfabetización mediática e informacional (AMI) promovidas por la Unesco y la Comisión Europea

\section{Conclusiones}

El aumento de la incidencia tecnológica en la vida cotidiana, en general, y en los procesos de administración pública, en particular, hacen necesaria la adaptación y la modernización de las administraciones públicas (AAPP) como instituciones y como organizaciones formadas por individuos. Para garantizar la prestación de servicios asociados al gobierno y la participación electrónica las AAPP necesitan alcanzar competencias mediáticas que se asocian a las competencias generales de la alfabetización mediática e informacional (AMI) promovidas por la Unesco y la Comisión Europea. Los cambios de alfabetización - de una tradicional a una mediática- no deben entenderse únicamente dentro de los centros educativos, sino que necesitan apropiarse en todas las organizaciones sociales tanto públicas como privadas.

Asimismo, diferentes instituciones requieren mediciones diferenciadas. A pesar de que pueden compartirse competencias mediáticas comunes, resulta necesario emprender un proceso de especificidad en su medición y evaluación institucional. Los centros educativos, las empresas y el sector público son instituciones con objetivos y funciones diferentes y, sobre todo en el criterio de comunicación, las competencias mediáticas necesitan adaptarse sobre los contextos de aplicación de las mismas, al tiempo que atienden a estándares internacionales diferenciados.

La investigación presentada evidencia la ausencia de indicadores específicos de AM para las AAPP y adecua una propuesta a partir de los marcos conceptuales y competenciales de la disciplina a las necesidades identificadas dentro de las AAPP. El estudio combina diversos métodos de investigación para la construcción de los indicadores y de su aplicación en un estudio piloto, al tiempo que analiza la viabilidad y los alcances de un cuestionario preparado para la medición de los indicadores propuestos.

Los indicadores presentados resuelven tres problemas concretos identificados en los estudios previos de medición de las competencias mediáticas en todos los ámbitos. En primer lugar, dan equilibrio a los diferentes factores que hacen parte del concepto holístico de la AM, antes centrados en aspectos técnicos. El nuevo marco de indicadores profundiza, sobre todo en el criterio de comunicación como uno de los pilares centrales del concepto de AM. En segundo lugar, aproximan el análisis al contexto propio de las AAPP al dotarlas de contenido específico sobre el área de estudio. Por último, la implementación de los indicadores a través de un cuestionario permite la construcción de una base de datos compuesta por múltiples variables que arrojan información para la toma de decisiones institucionales, en términos de promoción y formación de la AM entre sus trabajadores y como organismo público.

La aplicación del cuestionario sobre más de 58 individuos y 3 administraciones públicas induce a pensar, aunque con reservas, que el nivel de $\mathrm{AM}$ en las instituciones testadas es, sobre todo en competencias relacionadas con la comunicación, bajo. Tan sólo el $26 \%$ de los individuos encuestados ejecuta tareas creativas o de producción de contenido, el $50 \%$ no ha realizado nunca actividades colaborativas en internet y el $60 \%$ no realiza funciones relacionadas con el gobierno o la participación electrónica dentro de la AAPP. Las cifras anteriores - a pesar de ser únicamente resultados de una prueba piloto- dan que pensar en la necesidad de realizar más esfuerzos en la medición de la AM en diferentes contextos y, sobre todo, de realizar una mayor concientización sobre la importancia de la AM en la implementación de la administración pública del siglo XXI.

\section{Sólo el $26 \%$ de los encuestados ejecuta tareas creativas, el $50 \%$ no ha realizado nunca actividades colaborativas en internet, y el $60 \%$ no realiza funciones relacionadas con el gobierno o la parti- cipación electrónica}

\section{Notas}

1. A lo largo del texto usaremos indistintamente AM, alfabetización mediática - siguiendo la terminología de la UE- o AMI, alfabetización mediática e informacional, siguiendo el criterio de la Unesco.

2. Según la Comisión Europea (2009), la AM es "la capacidad de acceder a los medios de comunicación, comprender y evaluar con criterio diversos aspectos de los mismos y de sus contenidos". Este concepto abarca otras alfabetizaciones, relacionadas a formatos o tecnologías (Unesco, 2011), como por ejemplo: la alfabetización digital, referida a las habilidades más técnicas derivadas del uso de tecnología; la alfabetización cinematográfica, sobre competencias que derivan del uso del cine como forma de arte; o la alfabetiza- 
ción de noticias (news literacy), en relación con la capacidad de discernir entre información verídica y noticias falsas (Mihailidis, 2011), entre otras muchas alfabetizaciones.

3. Las entrevistas fueron realizadas en el Ayuntamiento de Sant Cugat del Vallès, en la que participaron la gerente de la AAPP y los responsables de recursos humanos y comunicación, y en el Parlamento de Cataluña, en la que participaron el gerente y la responsable de recursos humanos de la institución.

\section{Agradecimientos}

Los resultados presentados, fueron obtenidos en la implementación del proyecto Dinamic (Desarrollo de indicadores de alfabetización mediática individuales, corporativos y ciudadanos), investigación competitiva financiada en el marco del Programa Nacional de Proyectos de Investigación Fundamental No Orientada (I+D+I), dentro del VI Programa Nacional de Investigación Científica (Número de referencia: CSO2011-24327).

\section{Referencias}

Abad-Alcalá, Leopoldo (2014). “Diseño de programas de e-inclusión para la alfabetización mediática de personas mayores". Comunicar, v. 21, n. 42, pp. 173-180.

https://doi.org/10.3916/C42-2014-17

Aguaded-Gómez, José-Ignacio; Ferrés-Prats, Joan; CruzDíaz, María-del-Rocío; Pérez-Rodríguez, María-Amor; Sánchez-Carrero, Jaqueline (2011). El grado de competencia mediática en la ciudadanía andaluza. Huelva: Grupo Comunicar. ISBN: 9788493731625

http://rabida.uhu.es/dspace/bitstream/handle/10272/6892/ Grado_de_competencia_mediatica.pdf?sequence $=2$

Ainley, John; Fraillon, Julian; Gebhardt, Eveline; Schulz, Wolfram (2012). National assessment program: ICT literacy years 6 and 10 report 2011. Autralian Council for Educational Research (ACER).

https://research.acer.edu.au/ict_literacy/3

Aparici, Roberto; García-Matilla, Agustín (2016). “¿Qué ha ocurrido con la educación en comunicación en los últimos 35 años? Pensar el futuro". Espacios en blanco. Serie indagaciones, v. 26, n. 1.

https://goo.gl/cJE49y

Area, Manuel (2015). “Educar a la generación de los Millennials como ciudadanos cultos del ciberespacio. Apuntes para la alfabetización digital". Revista de estudios de juventud, n. 109, pp. 13-32.

http://www.injuve.es/sites/default/files/indice_109.pdf

Buckingham, David (2014). "Mapping and measuring media literacy. Concepts, processes and practices". London: English and Media Centre.

https://ddbuckingham.files.wordpress.com/2015/04/ media-literacy-concepts-processes-practices.pdf

Cabinet of Ministers of the Republic of Latvia (2008). Guidelines for the government communication policy 2008-2013. Riga, Latvia: State Chancellery.

http://bit.ly/2himds3
Capgemini Consulting (2007). The user challenge benchmarking. The supply of online public services. Brussels: Directorate General for Information Society and Media, European Commission.

http://www.umic.pt/images/stories/publicacoes200709/ egov_benchmark_2007.pdf

Capgemini Consulting (2010). eGovernment. Estudio sobre mejores prácticas en gobierno electrónico en Europa. Madrid: Ministerio de Política Territorial y Administración Pública. https://goo.gl/7SaNnL

Capgemini Consulting (2012). Estudio comparativo 2012 de los servicios públicos online en las Comunidades Autónomas. Resultados 6a Medición. Madrid: Fundación Orange. https://www.proyectosfundacionorange.es/docs/Estudio_ Comparativo_2012_Servicios_on_line.pdf

Cappello, Gianna; Felini, Damiano; Hobbs, Renee (2011). "Reflections on global developments in media literacy education: Bridging theory and practice". Journal of media literacy education, v. 3, n. 2, pp. 66-73.

http://digitalcommons.uri.edu/jmle/vol3/iss2/1

Comisión Europea (2006). “Comunicación de la Comisión al Consejo, al Parlamento Europeo, al Comité Económico y Social Europeo y al Comité de las Regiones". En: Plan de acción sobre administración electrónica i2010: acelerar la administración electrónica en Europa en beneficio de todos. Bruselas: Comisión Europea. COM/2014/015, n. 52014DC0015 de 25/04/2006. https://goo.gl/NzpTsQ

Comisión Europea (2007). “Comunicación de la Comisión al Parlamento Europeo, al Consejo, al Comité Económico y Social Europeo y al Comité de las Regiones - Un planteamiento europeo de la alfabetización mediática en el entorno digital". Bruselas: Comisión Europea. COM/2007/0833, n. 52007DC0833 de 20/10/2007.

https://goo.gl/PYVodW

Comisión Europea (2009). “Recomendación de la Comisión sobre la alfabetización mediática en el entorno digital para una industria audiovisual y de contenidos más competitiva y una sociedad del conocimiento incluyente". Bruselas: Comisión Europea, 2009/625/CE de 20/08/2009.

https://goo.gl/iGaVnU

Contreras-Pulido, Paloma (2014). La alfabetización mediática como herramienta de intervención en prisiones. Tesis doctoral. Universidad de Huelva.

https://dialnet.unirioja.es/servlet/tesis?codigo $=41386$

Costa-Badía, Pere-Oriol; Giraldo-Luque, Santiago (2013). "Las páginas web de los ayuntamientos, instrumentos de información y participación ciudadana”. En: La Porte Fernández-Alfaro, María-Teresa; Gutiérrez-García, Elena. Tendencias emergentes en la comunicación institucional. Barcelona: Editorial UOC. ISBN: 9788490297513

Dirección de Tecnologías de la Información y las Comunicaciones (DTIC) (2016). Las tecnologías de la información y las comunicaciones en las administraciones públicas. Informe Reina 2016. Madrid: Ministerio de Hacienda y Administraciones Públicas.

https://goo.gl/C9unMB 
Dirección de Tecnologías de la Información y las Comunicaciones (DTIC) (2016). Las tecnologías de la información y las comunicaciones en la administración local. Informe IRIA 2016. Madrid: Ministerio de Hacienda y Administraciones Públicas. https://ssweb.seap.minhap.es/portalEELL/doc/Manual_ Gestor_IRIA.pdf

Ferrés-Prats, Joan (2007). "La competencia en comunicación audiovisual: dimensiones e indicadores". Comunicar, v. 15, n. 29, pp. 100-107.

https://goo.gl/6UnzpG

Ferrés-Prats, Joan; Piscitelli, Alejandro (2012). “La competencia mediática: propuesta articulada de dimensiones e indicadores". Comunicar, v. 19, n. 38, pp. 75-82.

https://doi.org/10.3916/C38-2012-02-08

Frau-Meigs, Divina; Vélez, Irma; Flores-Michel, Julieta (eds.) (2017). Public policies in media and information literacy in Europe: cross-country comparisons. Reino Unido: Taylor \& Francis. ISBN: 9781317242277

Fundación Telefónica (2018). Sociedad digital en España 2017. Madrid, Barcelona: Fundación Telefónica; Ariel.

https://www.fundaciontelefonica.com/arte_cultura/ publicaciones-listado/pagina-item-publicaciones/itempubli/625

Giraldo-Luque, Santiago; Durán-Becerra, Tomás; Esteban-Abengozar, Almudena; Villegas-Simón, Isabel-María (2014). "MIL competences: from theory to practice. Measuring citizens' competences on media and information literacy". eLearning papers, n. 38, pp. 1-13.

https://goo.gl/wcUKRC

Hemant, Chittoo; Baboo, Nowbutsing (2010). "Strategies to increase e-government take-up: Looking beneath statistics". Global journal of management and business research, v. 10, n. 1, pp. 104-114.

https://journalofbusiness.org/index.php/GJMBR/article/ view/14/12

Hermida, Martin; Hielscher, Michael; Petko, Dominik (2017). "Medienkompetenz messen: Die entwicklung des medienprofis-tests in der Schweiz". MediePädagogik, pp. 38-60.

http://dx.doi.org/10.21240/mpaed/00/2017.06.02.X

Hernández-Sampieri, Roberto; Fernández-Collado, Carlos; Baptista-Lucio, Pilar (2006). Metodología de la investigación. México: McGraw-Hill. ISBN: 9789701057537

Hrdinová, Jana; Helbig, Natalie; Peters, Catherine-Stollar (2010). Designing social media policy for government: Eight essential elements. Albany: Center for Technology in Government.

https://www.ctg.albany.edu/publications/guides/social_ media_policy/social_media_policy.pdf

Horrocks, Ivan J. (2010). E-government: The development and evaluation of government online, Unit 97 of the MA in media \& communications (by distance learning). Department of Media and Communication, University of Leicester, United Kingdom.

López-Romero, Laura; Aguaded-Gómez, María-de-la-Cinta (2015). "La docencia sobre alfabetización mediática en las facultades de Educación y Comunicación”. Comunicar, v. 22, n. 44, pp. 187-195.

https://doi.org/10.3916/C44-2015-20

Lorincz, Barbara; Colclough, Graham; Tinholt, Dinand; Van-Oranje, Constantijn; Cattaneo, Gabriella; Jacquet, Laurent (2009). Smarter, faster, better egovernment. $8^{\text {th }}$ eGovernment benchmark measurement. Bruselas: Directorate General Information Society and Media, European Commission. https://goo.gl/jzp42d

Llorente-Cejudo, María-del-Carmen; Cabero-Almenara, Julio (2010). "Desarrollo de un instrumento sobre competencias TIC en alumnos universitarios". En: Congreso euro-iberoamericano de alfabetización mediática y culturas digitales. Universidad de Sevilla.

Margetts, Helen; Dunleavy, Patrick (2002). Better public services through e-government: academic article in support of better public services through e-government. National Audit Office report, HC 704-III session 2001-2. The Stationery Office, London, UK. http://eprints.Ise.ac.uk/21645

Martínez-Cerdá, Juan-Francisco; Torrent-Sellens, Joan (2014). "Alfabetización mediática y co-innovación en la microempresa: primeras evidencias para España". El profesional de la información, v. 23, n. 3, pp. 288-299.

https://doi.org/10.3145/epi.2014.may.09

Medina-Cambrón, Alfons; Ballano-Macías, Sonia (2015). "Retos y problemáticas de la introducción de la educación mediática en los centros de secundaria". Revista de educación, n. 369, pp. 135-158. https://doi.org/10.4438/1988-592X-RE-2015-369-293

Mihailidis, Paul (2011). News literacy: Global perspectives for the newsroom and the classroom. Bern: Peter Lang Publishing Inc. ISBN: 1433115646

Miret, Inés; Armendano, Cristina (2011). Lectura y bibliotecas escolares. Colección Metas Educativas 2021. Santillana; OEl; Aecid.

http://www.oei.es/historico/noticias/spip.php?article9241

Ng, Wan (2011). "Can we teach digital natives digital literacy?". Computers \& education, v. 59, n. 3, pp. 1065-1078. https://doi.org/10.1016/j.compedu.2012.04.016

Observatorio Audiovisual Europeo (2017). Mapping of media literacy practices and actions in EU-28. Estrasburgo: European Audiovisual Observatory. ISBN: 9789279644016 https://doi.org/10.2759/111731

ONU (2014). United Nations e-government survey 2014. E-government for the future we want. New York: Naciones Unidas. https://publicadministration.un.org/egovkb/en-us/Reports/ UN-E-Government-Survey-2014

ONU (2016). United Nations e-government survey 2016. E-government in support of sustainable development. New York: Naciones Unidas.

https://publicadministration.un.org/egovkb/en-us/Reports/ UN-E-Government-Survey-2016

Park, Sora (2012). "Dimensions of digital media literacy and the relationship to social exclusion". Media international Australia, v. 142, pp. 87-100. 
https://goo.gl/ReiKK4

Parlamento Europeo (2007). “Directiva 2007/65/CE del Parlamento Europeo y del Consejo, de 11 de diciembre de 2007, por la que se modifica la Directiva 89/552/CEE del Consejo sobre la coordinación de determinadas disposiciones legales, reglamentarias y administrativas de los Estados miembros relativas al ejercicio de actividades de radiodifusión televisiva". Diario oficial de la Unión Europea, n. L 332/27, de 18/12/2007, pp. 27-45.

https://goo.gl/WBPV2K

Pereira, Sara; Pinto, Manuel; Moura, Pedro (2015). Níveis de literacia mediática: Estudo exploratório com jovens do 12 ano. Braga, Portugal: CECS - Centro de Estudos de Comunicação e Sociedade, Universidade do Minho. ISBN: 978 9898600417

http://www.lasics.uminho.pt/ojs/index.php/cecs_ebooks/ article/view/2117/2036

Pérez-Rodríguez, María-Amor; Delgado-Ponce, Águeda (2012). "De la competencia digital y audiovisual a la competencia mediática: dimensiones e indicadores". Comunicar, v. 20, n. 39, pp. 25-34.

https://doi.org/10.3916/C39-2012-02-02

Pérez-Tornero, José-Manuel; Celot, Paolo (2009). Study on assessment criteria for media literacy levels. A comprehensive view of the concept of media literacy and an understanding of how media literacy levels in Europe should be assessed. Bruselas: EAVI; UAB; Comisión Europea; Final report. http://ec.europa.eu/assets/eac/culture/library/studies/ literacy-criteria-report_en.pdf

Pérez-Tornero, José-Manuel; Durán-Becerra, Tomás; Tejedor-Calvo, Santiago (2015). "MIL Policies in Europe 2004-2014: The uniqueness of a policy and its connection to Unesco". In: Singh, Jagtar; Grizzle, Alton; Yee, Sin-Joan; Hope-Culver, Sherri (eds.) (2015). Media and information literacy for the sustainable development goals. Milid yearbook, pp. 139-151. Paris: Unesco. ISBN: 9789187957130 https://milunesco.unaoc.org/wp-content/uploads/2015/07/ milid_yearbook_20151.pdf

Pérez-Tornero, José-Manuel; Varis, Tapio (2010). Media literacy and new humanism. Moscú. Unesco Institute for Information Technologies in Education.

http://iite.unesco.org/pics/publications/en/files/3214678.pdf

Ribeiro-Pessoa, María-Teresa; Hernández-Serrano, María-José; Muñoz-Rodríguez, José-Manuel (2015). “Aprendizaje informal, alfabetización mediática e inclusión social. Descripción de una experiencia". Profesorado. Revista de cur- rículum y formación del profesorado, v. 19, n. 2, pp. 75-91. http://www.ugr.es/ recfpro/rev192ART5.pdf

Sardi, Ximena-Castro; Mlikota, Kristina (2002). Overview on e-governance. Working paper prepared in the framework of the ICT cross-cutting project ICTs as tools for improving local governance. Unesco.

Subirats, Joan (2013). "Preámbulo". En: Hoffman, Andrés; Rodríguez-Alujas, Álvaro y Bojórquez-Pereznieto, José-Antonio (coords.). La promesa del gobierno abierto. México: Itaip-Infodf.

http://www.alejandrobarros.com/wp-content/uploads/2016/04/ La_promesa_del_Gobierno_Abierto.pdf

Tayie, Samy (2005). Research methods and writing research proposals. El Cairo: Center for Advancement of Postgraduate Studies and Research in Engineering Sciences, Faculty of Engineering, Cairo University. ISBN: 9774030133 http://www.pathways.cu.edu.eg/subpages/training_ courses/C3-Research-EN.pdf

Tilleul, Camille; Fastrez, Pierre; De Smedt, Thierry (2014). "Evaluating media literacy and media education competences of future media educators". In: Kotilainen, Sirkku; Kupiainen, Reijo (eds.). Reflections on media education futures. The clearinghouse yearbook Nordicom. Göteborg - Suecia: Nordicom. Camille Tilleul, Pierre Fastrez \& Thierry De Smedt ISBN: 9789187957161

http://www.nordicom.gu.se/sites/default/files/publikationerhela-pdf/yearbook_2015.pdf

Tucho, Fernando; Fernández-Planells, Ariadna; Lozano-Estivalis, María; Figueras-Maz, Mònica (2015). "La educación mediática, una asignatura pendiente en la formación de periodistas, publicitarios y comunicadores audiovisuales". Revista latina de comunicación social, n. 70, pp. 689-702. http://dx.doi.org/10.4185/RLCS-2015-1066en

Unesco (2011). Alfabetización mediática e informacional. Curriculum para profesores. Paris: Unesco. ISBN: 97895918 07878 http://unesdoc.unesco.org/images/0021/002160/216099S.pdf

Unesco (2013). Global media and information literacy assessment framework: Country readiness and competencies. Paris: Unesco. ISBN: 9789230012212 http://unesdoc.unesco.org/images/0022/002246/224655e.pdf

Vergez, Christian; Wang, Yih-Jeou (2010). Denmark: Efficient e-government for smarter public service delivery. Paris: OECD.

http://www.oecd.org/gov/digital-government/45382562.pdf 


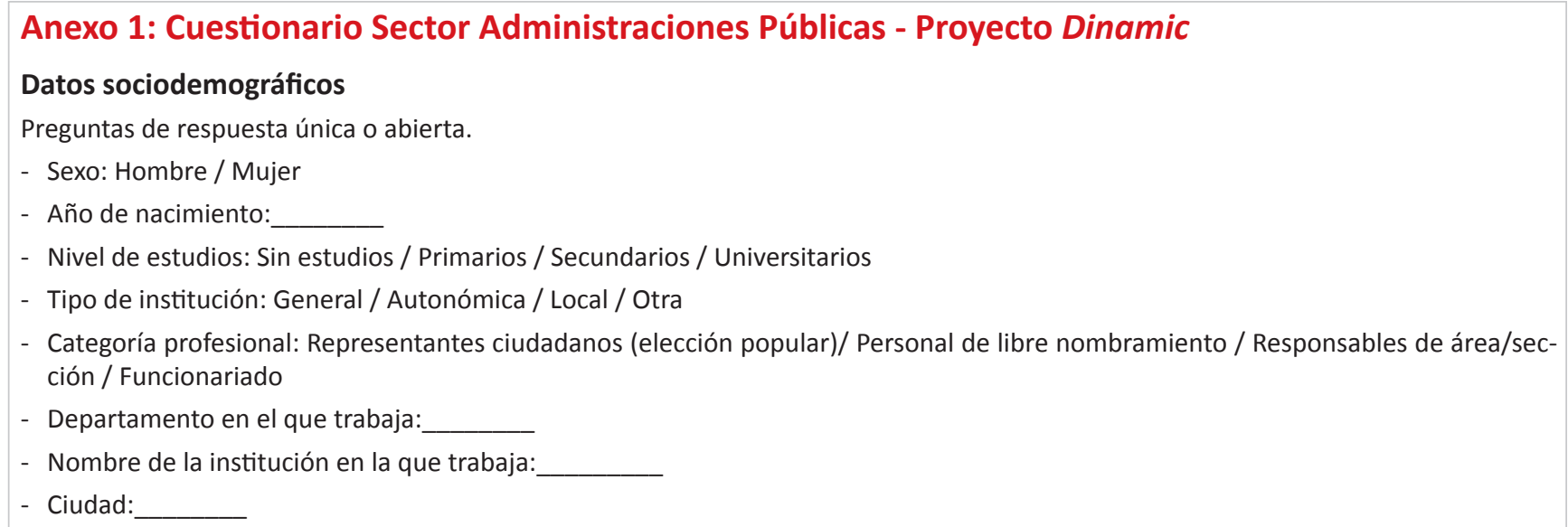

\section{BLOQUE 1: Infraestructura y organización de la institución}

Todas las preguntas: Sí / No / No sabe

- En la actualidad, ¿̇dispone usted de acceso a internet en su lugar de trabajo

- En la actualidad, ¿̇e qué dispositivos o medios proporcionados por la institución en la que trabaja dispone usted para realizar actividades laborales?: Ordenador / Tableta / Teléfono móvil / Dispositivos para grabar o reproducir imágenes, audio o videos (cámaras, proyectores, grabadoras) / Reproductores de video o audio (p.ej. radio o TV)

- ¿ ¿De cuáles de los siguientes canales de comunicación en línea dispone la institución en la que trabaja?: Página web o blog / Microblog (p. ej. Twitter) / Perfiles en redes sociales (p. ej. Facebook o LinkedIn) / Websites para compartir contenido (p. ej. YouTube, Flickr o Picasa)

- En el último año, ¿su institución ha desarrollado algún tipo de actividad de formación con los trabajadores en los siguientes ámbitos?: Ofimática básica (procesamiento de textos, hojas de cálculo básicas, presentaciones, etc.) / Uso de internet / Uso avanzado de aplicaciones (tratamiento de textos avanzados, bases de datos, etc.) / Multimedia (uso del vídeo digital, equipo de audio, creación de páginas web, etc.) / Seguridad en internet

- ¿ ¿Su institución tiene regulación o normas de uso de los siguientes dispositivos y/o recursos de internet en el horario laboral?: Ordenadores o tabletas / Móviles / Blogs (p. ej. Blogspot) / Redes sociales (p. ej. Facebook o Tuenti) / Mensajería y chats (p.ej. Whatsapp)

- ¿Cuáles de las siguientes informaciones son públicas en su institución?: Datos sobre la ubicación, historia o funciones / Datos sobre los presupuestos y gastos / Personal adscrito / Actividades y/o proyectos.

\section{BLOQUE 2: Ámbito personal}

Preguntas de frecuencia: Cada día o casi cada día, Al menos una vez a la semana, Al menos una vez al mes, Menos de una vez al mes, No la he realizado.

\section{Bloque 2.1. Uso de las Tecnologías de la Información y la Comunicación}

- En los últimos tres meses, ¿con qué frecuencia ha realizado usted las actividades siguientes? Ver televisión / Ir al cine / Escuchar radio / Leer un libro / Leer un periódico impreso / Leer la prensa en internet / Jugar a un videojuego / Usar un ordenador / Usar el teléfono móvil / Usar internet en el ordenador / Usar internet en el teléfono móvil

- En los últimos tres meses, ¿con qué frecuencia ha realizado usted las actividades siguientes?: Usar un procesador de texto (p. ej. Word) / Usar hojas de cálculo (p. ej. Excel) / Crear o gestionar bases de datos (p. ej. Access) / Crear presentaciones digitales incluyendo imágenes, sonidos, vídeos o tablas, editar fotos digitales u otras imágenes en el ordenador.

- En los últimos tres meses, ¿con qué frecuencia ha utilizado usted internet para realizar las actividades siguientes?: Compartir contenido creado por usted (p. ej. textos, imágenes o vídeos) / Ver vídeos, programas de TV o películas / Comprar o vender productos o servicios (p. ej. un billete de avión) / Buscar trabajo / Utilizar lenguaje HTML (p.ej. ajustes en un blog) / Descargar vídeos, programas de TV o películas / Descargar e instalar software en un ordenador / Resolver problemas técnicos en un ordenador / Utilizar servicios bancarios.

- Para encontrar el siguiente documento, ¿cuál de entre las siguientes opciones escribiría preferentemente en la barra de búsquedas de su navegador? [respuesta única]:

Sociedades +conocimiento +unesco

Sociedades +conocimiento

Hacia las sociedades del conocimiento -unesco.

"Hacia la sociedad unesco"

Ninguna de las anteriores

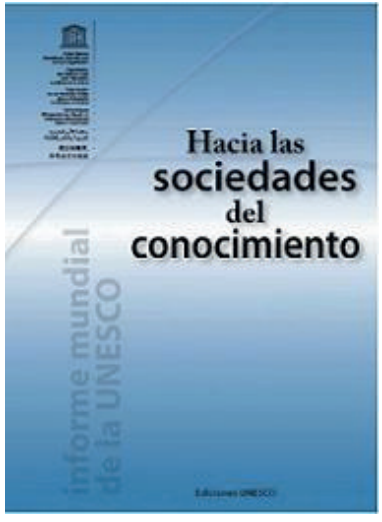


- ¿Para qué utiliza usted "la nube" de internet (p. ej. Dropbox o Google Drive)? [Sí / No]: Almacenar archivos o documentos / Crear archivos o documentos / Editar archivos o documentos / Compartir archivos o documentos.

- En los últimos tres meses, ¿con qué frecuencia ha realizado usted con su móvil las tareas siguientes?: Hacer una llamada / Enviar un mensaje de texto (sms) / Participar en un chat (p. ej. Whatsapp) / Jugar / Hacer una fotografía / Grabar un vídeo / Instalar una aplicación (App) / Encontrar un lugar (p. ej. una farmacia).

\section{Bloque 2.2. Conocimiento de los medios}

- Indique el grado de acuerdo o desacuerdo respecto a la siguiente afirmación: "Me considero capacitado para realizar las tareas siguientes" [Muy de acuerdo / De acuerdo / En desacuerdo / Muy en desacuerdo]: Buscar información adecuada a sus necesidades / Comprender noticias de ámbito general / Comprender información gráfica / Diferenciar entre el contenido fiable del no fiable en la búsqueda de información / Contrastar la información recibida a través de los medios de comunicación.

- De entre los medios de comunicación siguientes, ¿cuáles identificaría como de titularidad pública y cuáles de titularidad privada?: SER / RNE/ Onda cero / La sexta / La 1 / Cuatro

- Si usted encuentra en un diario los títulos propuestos a continuación, ¿cómo los clasificaría de acuerdo a los criterios de la siguiente tabla? [Opinión / Información noticiosa / No sabe]: España bate de nuevo el récord con 45 trasplantes en un día / El Barça paga 'por si acaso' / América Latina, ni de rojo, ni a la izquierda / La banca debe a las comunidades de vecinos 342 millones de euros.

- Según la Ley General de la Comunicación Audiovisual, ¿¿cuál es el horario estipulado de protección para menores en la televisión? [respuesta única]: Sábados y Domingos de 08:00 a 13:00 / Entre las 06:00 y las 22:00 / De 08:00 a 09:00 y de 17:00 a 20:00 / No hay horario de protección para menores / No sabe

- ¿El tiempo dedicado a contenidos educativos en los medios de comunicación está regulado o sujeto a normas legales?: Sí / No / No sabe

- Si usted quiere conocer el número de mujeres que iniciaron sus estudios universitarios en el curso 2012-2013 en España, ¿cuál de entre todos los enlaces propuestos le parece el mejor para encontrar la información que busca? [respuesta única]

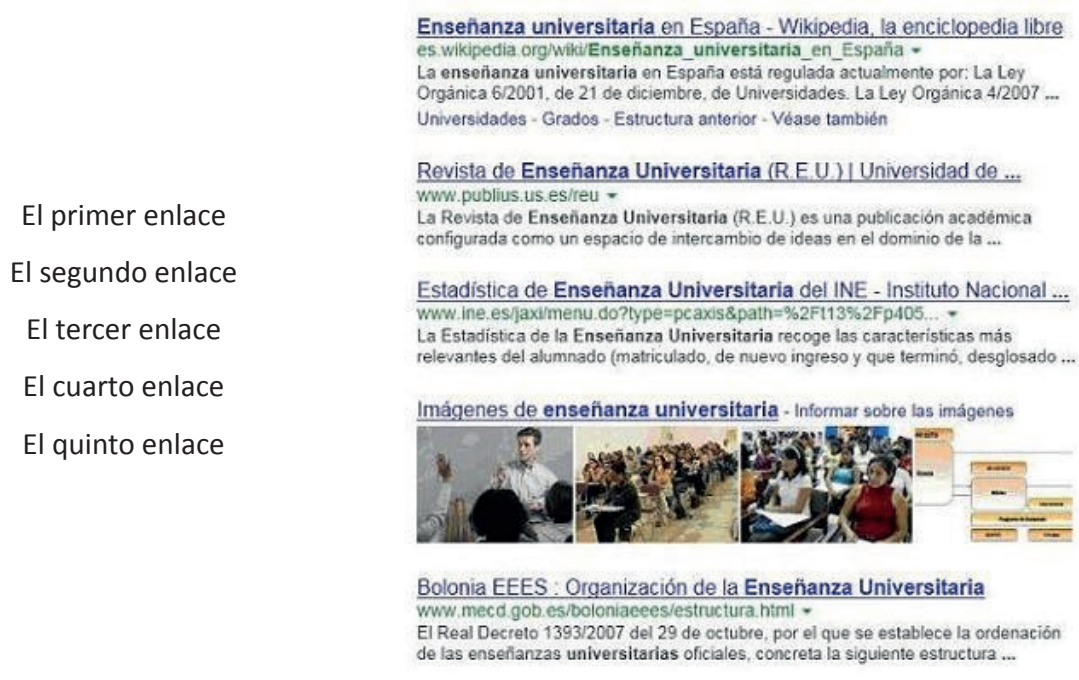

- En el último año, ¿̇ha realizado alguna de las siguientes actividades relacionadas con la seguridad digital? [Sí / No / No uso]: Establecer contraseñas para el acceso a sus dispositivos (p. ej. ordenador, móvil, etc.) / Gestionar el historial de su navegador de internet / Gestionar en internet los datos que desea recordar de la función Autocompletar.

- ¿Ha realizado usted las siguientes actividades relacionadas con la privacidad de sus cuentas en las redes sociales (p. ej. Facebook o Tuenti)? [Sí / No / No uso]: Gestionar quién puede ver sus datos personales y su perfil / Configurar las opciones de geolocalización de sus publicaciones / Informarse sobre las normas de propiedad de sus publicaciones / Personalizar las opciones de privacidad / Solicitar autorización previa para etiquetar a otros miembros de la red social en sus publicaciones

- Si usted elabora un proyecto multimedia (p. ej. power point, prezi, vídeos, etc.) con fines laborales, ¿cuáles de los siguientes elementos cree que puede utilizar? [respuesta única]: Canciones, vídeos e imágenes si ya están disponibles en cualquier página o servidor de internet. / Todos los materiales accesibles, si tienen una licencia que lo permita. / Fragmentos de imágenes y canciones, pero no de vídeos. / No puedo usar fragmentos de ningún contenido multimedia publicado en internet.

\section{Bloque 2.3. Prácticas comunicativas}

- En los últimos tres meses, ¿̇ha creado usted algunos de los productos comunicativos siguientes? [Sí / No]: Escribir un artículo para periódicos, revistas u hojas informativas / Escribir literatura de cualquier tipo (p. ej. un libro o un poema) / Crear un producto audiovisual o sonoro de cualquier tipo (p. ej. una foto o un vídeo) / Crear un blog o actualizar el que ya tiene / Diseñar un personaje o avatar en sitios Web como Habbo, Gaia online o Second Life.

- En el último año, ¿̇ha utilizado usted internet en el ámbito personal para realizar las acciones siguientes? [Sí / No / Prefiere no contestar]: Escribir una carta a un medio de comunicación / Contactar a un político o partido político / Donar dinero a una causa cívica 
o política / Firmar una petición para apoyar una causa política o social / Realizar peticiones en línea a las autoridades públicas / Participar en debates o comentar sobre asuntos políticos o cívicos en un blog, en una red social o en un medio de comunicación / Colaborar con otros ciudadanos en un proyecto colectivo

En los últimos tres meses, ¿con qué frecuencia ha utilizado usted las redes sociales (p. ej. Facebook o Tuenti) para realizar algunas de las acciones siguientes?: Enviar un mensaje / Establecer contacto con personas desconocidas / Compartir información creada por otros medios/usuarios / Publicar un estado o compartir información creada por usted mismo / Jugar / Buscar información sobre conocidos, amigos o familiares

\section{BLOQUE 3: Ámbito profesional}

En los últimos tres meses, ¿con qué frecuencia ha utilizado usted internet para realizar las actividades siguientes?: Crear textos incluyendo enlaces e imágenes / Visitar comunidades o foros relacionados con su trabajo / Participar en una red colaborativa/ profesional / Participar en programas de e-learning

En el último año, ¿̇ha utilizado usted internet para alguna de las tareas laborales que se mencionan a continuación? Recolectar materiales o recursos para el desarrollo de mi actividad / Preparar presentaciones / Descargar o cargar material en el sitio web de la institución / Utilizar programas de gestión del tiempo y/o actividades relacionadas con la institución / Compartir documentos / información con otros miembros de la institución

¿Su trabajo está relacionado con alguno de los siguientes servicios del gobierno electrónico? [Sí / No]: Ofrecer información al ciudadano / Ofrecer información de actualidad sobre la gestión de la institución / Atender de manera virtual al ciudadano / Fomentar la participación del ciudadano / Difundir y promover servicios para el ciudadano / Difundir proyectos de la institución / Promover el desarrollo económico, social y/o cultural del entorno de actuación de la institución / Realizar tareas de rendición de cuentas.

\section{Colección de libros de bolsillo El profesional de la información (Editorial UOC) Últimos títulos publicados}
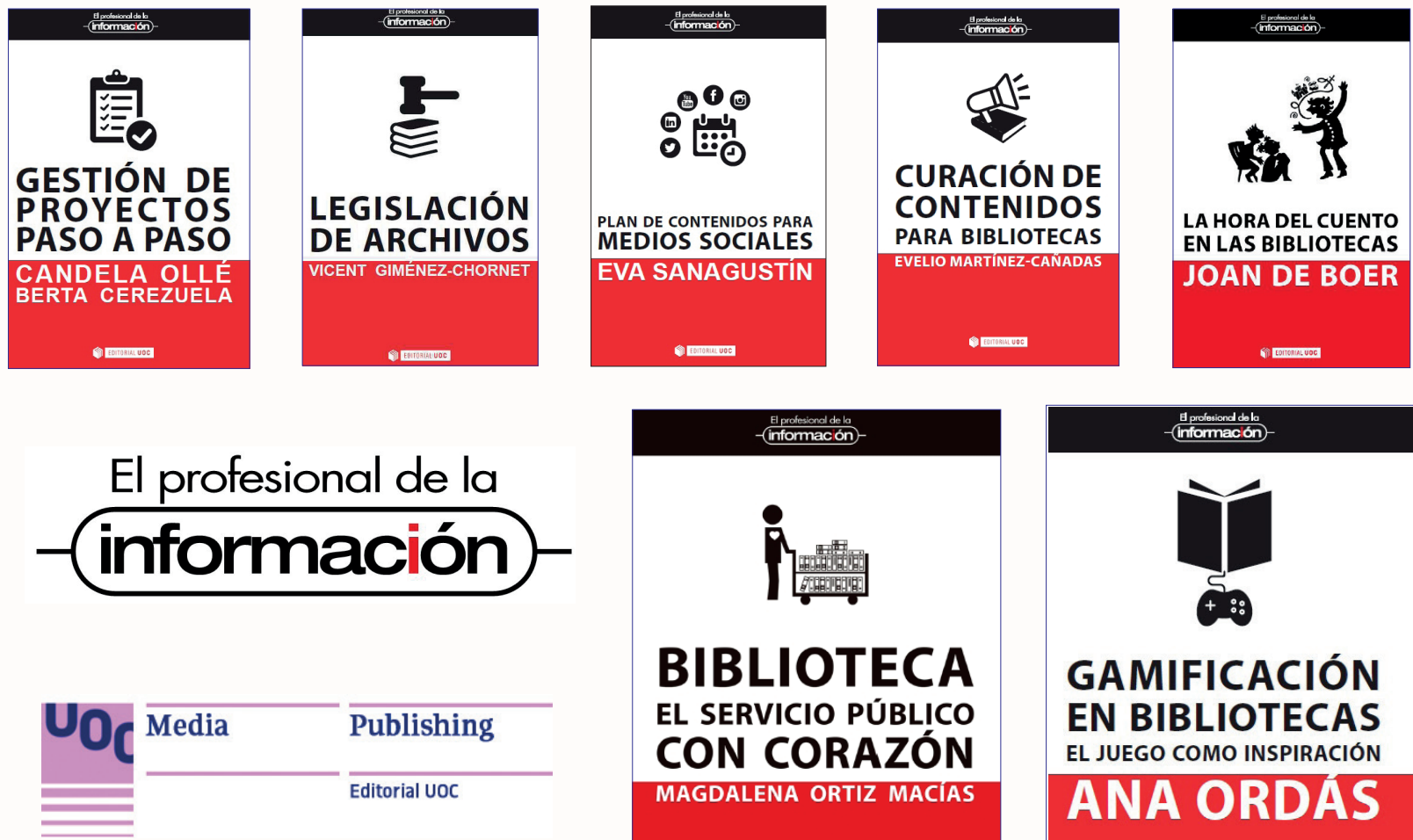

$\overline{\text { Media }} \overline{\text { Publishing }}$
$\overline{\text { Editorial uoc }}$
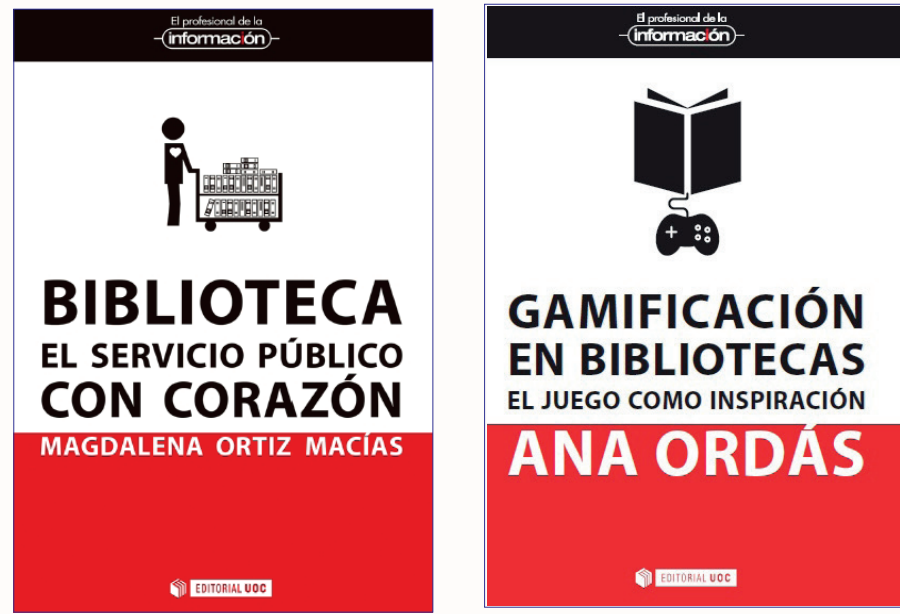

Más información: http://www.elprofesionaldelainformacion.com/libros.html 